\title{
Aspectos clínicos, hematológicos, bioquímicos e citopatológicos do tumor venéreo transmissível em cães tratados com sulfato de vincristina
}

\author{
[Clinical, haematological, biochemical and cytological aspects of canine transmissible venereal \\ tumor in dogs treated with vincristine sulfate]
}

\section{"Artigo Científico/Scientific Article"}

\author{
Miriam Aparecida Queiroz Barbosa Ferreira ${ }^{1,2}$, Mirian Nogueira Teixeira ${ }^{3}$, Clayton Charles \\ Dantas Carvalho $^{3}$, Bruno Henrique Albuquerque Paiva ${ }^{4}$, Vanessa Carla Lima Silva ${ }^{2}$, Fernanda \\ Lúcia Passos Fukahori², Michelle Suassuna Azevedo Rêgo², Mirella Bezerra de Melo Colaço \\ Dias $^{2}$, Evilda Rodrigues Lima ${ }^{2,3, *}$
}

\author{
${ }^{1}$ Faculdade Instituto Brasileiro de Gestão e Marketing, Recife-PE, Brasil. \\ ${ }^{2}$ Programa de Pós-Graduação em Ciência Veterinária, Universidade Federal Rural de Pernambuco, Recife-PE, Brasil. \\ ${ }^{3}$ Departamento de Medicina Veterinária, Universidade Federal Rural de Pernambuco, Recife-PE, Brasil. \\ ${ }^{4}$ Médico Veterinário autônomo, Recife-PE, Brasil. \\ *Autor para correspondência/Corresponding author: E-mail: evilda17@ @otmail.com
}

\begin{abstract}
Resumo
Com o objetivo de avaliar os aspectos clínicos, hematológicos, bioquímicos e citopatológicos de cães com tumor venéreo transmissível (TVT) tratados com o sulfato de vincristina foram selecionados 10 cães sem distinção de sexo, raça ou idade que tiveram o diagnóstico de TVT pelo exame citopatológico, dos quais foram colhidas amostras de sangue para realização de hemograma e dosagens bioquímicas. Os cães foram tratados com o sulfato de vincristina na dose de $0,75 \mathrm{mg} / \mathrm{m} 2 \mathrm{com}$ administração intravenosa a cada sete dias durante seis semanas. Dos 10 cães avaliados e acometidos pelo TVT, 70\% eram fêmeas e 30\% machos, com média de

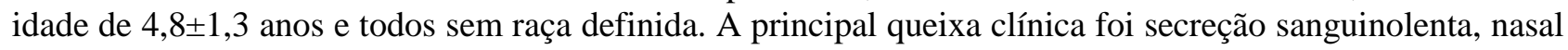
e/ou genital. Após a quimioterapia, apenas o sangramento vulvar apresentou diferenças estatisticamente significativas $(\mathrm{p}<0,05)$ a partir de 21 dias, onde $100 \%$ dos cães não apresentaram mais sangramentos. $\mathrm{Na}$ classificação citopatológica, observou-se que $50 \%$ dos tumores foram do tipo plasmocitário, $30 \%$ misto e $20 \%$ linfocitário. A alteração hematológica observada foi à diminuição na contagem dos bastonetes $(\mathrm{p}=0,042)$ no início e após sete dias, enquanto que na bioquímica sérica foi constatado aumento na dosagem sérica de fósforo $(p=0,024)$ com resultados estatisticamente significativos $(p<0,05)$. Concluiu-se que a citologia aspirativa por agulha fina e o imprint foram métodos eficazes, simples e seguros para o diagnóstico do TVT e que independente da classificação tumoral, houve resposta satisfatória de todos os pacientes ao tratamento com o sulfato de vincristina. Um protocolo a partir de seis aplicações do quimioterápico, com intervalos de sete dias entre as aplicações se mostrou eficiente para o tratamento do TVT com regressão completa da neoplasia.
\end{abstract}

Palavras-Chave: antineoplásico, cão, linfossarcoma venéreo, tumor de Sticker.

\begin{abstract}
In order to evaluate the clinical, haematological, biochemical, and cytological aspects of dogs with transmissible venereal tumor (TVT) treated with vincristine sulfate. Ten dogs were selected without distinction of sex, breed, or age who were diagnosed with TVT by cytological examination. Blood samples were collected for hemogram and biochemical levels. The dogs were treated with vincristine sulfate at a dose of $0.75 \mathrm{mg} / \mathrm{m} 2$ by intravenous administration every seven days, for six weeks. Of the 10 dogs evaluated with TVT, $70 \%$ were female and $30 \%$ male, with a mean age of $4.8 \pm 1.3$ years; all were mixed breed. The main clinical complaint was bloody nasal and/or genital discharge. After chemotherapy, only the vulvar bleeding presented statistically significant differences $(\mathrm{p}<0.05)$ from 21 days, and $100 \%$ of the dogs showed no further bleeding. On cytological classification, it was observed that $50 \%$ of the tumors were of the plasma cell type, $30 \%$ mixed, and $20 \%$ lymphocytic. The hematological abnormalities observed were in relation to the reduced rod count $(\mathrm{p}$ $=0.042)$ at the beginning and after seven days and increase of serum phosphorus $(p=0.024)$ with statistically
\end{abstract}


significant results $(\mathrm{p}<0.05)$. It is concluded that fine-needle aspiration and imprint cytology are effective methods, simple and safe exams, for diagnosis and classification of transmissible venereal tumor, and regardless to the type of TVT, there was a satisfactory response to chemotherapy with a vincristine sulfate base. A protocol with six applications of chemotherapy at a seven-day interval between applications proved to be efficient for treatment of canine TVT with total regression of tumor.

Key-words: antineoplasm, dog, venereal lymphosarcoma, Sticker tumor.

\section{Introdução}

O tumor venéreo transmissível (TVT) foi constatado em todos os continentes, com maior prevalência nas zonas de clima tropical e subtropical (Rogers et al., 1998). Acomete a espécie canina, apresentando uma predominância maior em animais jovens, errantes e sexualmente ativos (Rogers et al., 1998; Silva et al., 2007). A quimioterapia como único fármaco tem-se mostrado eficiente, sendo ainda o método de tratamento mais indicado (Daleck et al., 2009; Lima et al., 2013). Para o TVT, oncologistas veterinários sugerem eficiente a quimioterapia citotóxica, em que cerca de $90 \%$ dos cães respondem a terapia com o sulfato de vincristina (Johnson, 1994; Daleck et al., 2009), sendo apenas uma pequena porcentagem resistente ao tratamento (Daleck et al, 2009). A duração total do tratamento pode variar de quatro a seis semanas, e os animais permanecem livres da neoplasia (Johnson, 1994; Corona et al., 2004; Greatti et al., 2004).

Apesar da reconhecida eficácia da ação antineoplásica da vincristina e de seus homólogos, sua utilização crescente na oncologia veterinária tem colocado em evidência muitos dos seus efeitos colaterais indesejáveis, dentre os quais merecem destaque as ações neurotóxica e citostática não seletiva, podendo esta última levar a uma depressão de sistema celular de renovação rápida, tal como acontece com o tecido sanguíneo (Alleman e Harvey, 1993; Santana, 2000; Faro et al., 2008). Os principais efeitos colaterais da vincristina são alterações neurológicas, dermatológicas, hematológicas e gastrintestinais. Apesar de não ser frequente, em cães, há relatos de neuropatia periférica, parestesia, déficit proprioceptivo, íleo paralítico e constipação (Rodaski e Nardi, 2007).

Diniz et al. (1999) verificaram que os cães tratados com superdosagem vincristina apresentaram episódios de vômitos, acompanhados de diarreia, anorexia, melena, constipação, alopecia e necrose nos locais de aplicação do agente, além de desidratação e emagrecimento progressivo. Devido à supressão significativa da medula óssea provocada pela vincristina, faz-se necessário um acompanhamento do quadro hematológico dos cães sob essa terapia, uma vez que não existem antídotos específicos para a toxicose provocada por esse fármaco (Rosenthal, 1995). Diante da importância do TVT na clínica de pequenos animais, existe a necessidade de esclarecimentos de alguns aspectos relacionados a esta neoplasia. Desta forma, objetivou-se avaliar a eficácia do sulfato de vincristina em cães portadores de TVT, as características das lesões, o tempo de regressão e efeitos colaterais, realizando o acompanhamento clínico, hematológico, bioquímico e citopatológico de cães portadores desta doença.

\section{Material e Métodos}

Esta pesquisa foi realizada no período de março a agosto de 2015 no Hospital Veterinário e Laboratório de Patologia Clínica do Departamento de Medicina Veterinária (DMV) da Universidade Federal Rural de Pernambuco (UFRPE) e no laboratório particular de Anatomia Patológica, na cidade de Recife, Pernambuco.

Foram selecionados 10 cães sem distinção de sexo, raça ou idade com suspeita de TVT, que tiveram seu diagnóstico confirmado com o exame citológico. Os cães foram avaliados semanalmente antes da administração do quimioterápico para observação da remissão tumoral e de possíveis alterações clínicas e/ou laboratoriais que impossibilitasse o tratamento.

Em cada animal, foi colhido $6 \mathrm{~mL}$ de sangue venoso, com seringas descartáveis estéreis de 10 $\mathrm{mL}$, por meio de venopunção da cefálica ou da jugular externa, sendo $2 \mathrm{~mL}$ colocados em tubo plástico tipo (Vacutainer®) contendo anticoagulante (EDTA-K3) para a realização do hemograma. Foram feitas colheitas de sangue antes e após $(7,15,21,28$ e 35 dias) o tratamento quimioterápico, totalizando seis colheitas por animal. O hemograma foi realizado com o auxílio de analisador hematológico veterinário (pocH100iV-Diff-Roche $\left.{ }^{\circledR}\right)$ enquanto a morfologia celular e a contagem diferencial das células foram realizadas após a confecção de esfregaços 
sanguíneos em lâminas de vidro e corados pelo método panótico rápido (Instat-Prov®- Newprov).

Para as análises bioquímicas, foram transferidos $4 \mathrm{~mL}$ de sangue para um tubo plástico tipo (Vacutainer®) sem anticoagulante, que foi posteriormente centrifugado. Após a formação do coágulo, a amostra foi colocada em centrífuga Excelsa Baby II modelo 206-R® (Fanem, São Paulo-Brasil) com a velocidade de $500 \mathrm{G}$ durante 10 minutos para a obtenção do soro.

As análises bioquímicas foram realizadas em analisador bioquímico automático Labmax 240®, com a utilização de kits comerciais (Labtest Diagnóstica, MG, Brasil), de acordo com as técnicas descritas a seguir: ácido úrico: método enzimático de Trinder; albumina: método verde de bromocresol (VBC) com tampão citrato; proteína sérica total: método biureto; ALT (alanina aminotransferase): método cinético UV - IFCC; AST (aspartato aminotransferase): método cinética UV - IFCC; colesterol: método precipitação com ácido fosfotungstico e cloreto de magnésio; triglicerídeos: método enzimático de Trinder; oxidase; ureia: método enzimático colorimétrico; creatinina: método Labtest - reação de Jaffé; Picrato sem precipitação; FA (fosfatase alcalina): método Bowers e Mccomb modificado (substrato p-nitrofenilfosfato); cálcio: método arsenazo III; Fósforo: método Labtest (fosfomolibdato, molibdato); Magnésio: método Labtest; magon sulfonado, azul de xilidil e potássio: método enzimático em modo cinético.

Foram colhidas amostras das lesões por meio de imprint para realização de exame citopatológico e no caso de TVT nasal e nodulações cutâneas foram colhidos materiais por citologia aspirativa com agulha fina. A execução da punção passou pelas seguintes etapas: a agulha, acoplada à seringa, foi inserida na lesão previamente limpa com Solução fisiológica $(\mathrm{NaCl}$ a $0,9 \%$ ), realizou-se pressão negativa e, sem retirar a agulha de dentro da massa, reposicionou-se o conjunto com movimentos de vaivém, descrevendo um leque, permitindo assim, a coleta de uma área significativa do tumor.

A citologia por imprint foi realizada por impressão da massa em três lâminas histológicas com extremidade fosca e, com auxílio de uma lâmina extensora, distendido por meio de compressão suave. Os esfregaços da punção aspirativa e do imprint foram secos ao ar ambiente e foi utilizado o método de coloração Diff Quick para avaliação em microscopia de luz. Utilizou-se microscópio óptico para leitura dos exames citológicos, seguindo os critérios: observação em aumento de 100X para avaliação de celularidade, distribuição e qualidade da coloração; 200X para as características de esfoliação e avaliação dos tipos celulares e, por último aumento de 400X para análise morfológica individual das células, tais quais as características citoplasmáticas, cromatina nuclear e nucléolos.

Os cães foram submetidos a aplicações semanais com o sulfato de vincristina após serem avaliados clinicamente e laboratorialmente para receber o tratamento na dose de $0,75 \mathrm{mg} / \mathrm{m} 2$ por via endovenosa (EV), utilizando seringas descartáveis de $1 \mathrm{~mL}$ para aplicação da medicação. $\mathrm{Na}$ aplicação do quimioterápico, utilizou-se a solução de $\mathrm{NaCl}$ a $0,9 \%$, com equipo macrogotas e cateter n. 22 ou 24, escolhidos de acordo com o porte dos pacientes. Foram feitas seis aplicações, com intervalos de sete dias entre cada aplicação. Para realização da quimioterapia, foi necessário que os animais apresentassem contagem de leucócitos maior e/ou igual a $2.000 \mathrm{~mm} 3$ no dia zero e antes de cada sessão.

Durante o procedimento de quimioterapia, utilizou-se equipamentos de proteção individual composto por avental descartável de mangas longas, óculos de plástico descartável, máscara de carvão ativado e luvas descartáveis. Após cada tratamento, as lesões foram fotografadas e mensuradas com paquímetro para observação da remissão tumoral. Com o desaparecimento do tumor, realizou-se uma nova colheita de material por meio de swab e a amostra foi encaminhada para o Laboratório de Patologia (DMV-UFRPE) para avaliação da ausência das células tumorais, sendo esse o critério para alta médica.

A análise estatística descritiva dos dados foi realizada por meio de tabelas e gráficos, sendo os valores expressos como média \pm desvio-padrão. As diferenças das médias entre os períodos foram determinadas por meio da Análise de Variância (ANOVA), seguida, quando detectada diferença, pelo teste de comparações múltiplas de Tukey como post hoc teste. Para os valores com proporções em percentuais, utilizou-se o teste da Razão de Verossimilhança, e os valores considerados significativos quando $\mathrm{p}<0.05$. Para todas as análises, utilizou-se o Programa SPSS versão 20.0. 


\section{Resultados e Discussão}

Os 10 cães avaliados acometidos pelo TVT apresentaram o seguinte perfil: $70 \%(\mathrm{n}=7)$ eram fêmeas e $30 \%(n=3)$ machos, com média de idade de 4,8 $\pm 1,3$ anos; $60 \%$ tinham cinco anos de idade; $50 \%$ tinham acesso à rua; $50 \%$ tiveram uma ou mais gestações e $90 \%$ não eram esterilizados, além de $100 \%$ dos animais serem sem raça definida (SDR).

Gandotra et al. (1993) relataram que o TVT apresentou maior frequência em fêmeas, com idade média de três anos, animais mestiços e com predomínio na região genital. Sousa et al. (2000) relataram que cães machos com idade de um a 15 anos (média de sete anos) foram os mais afetados. Estudos descreveram a incidência de TVT em animais de dois a cinco anos (DALECK et al, 2009). Tem sido observado que o TVT acomete principalmente cães jovens, errantes e sexualmente ativos (Rogers et al., 1998; Lima et al., 2011). Os cães SRD fazem parte do grupo de risco para o TVT (Flores et al.,1993; Sousa et al., 2000), sendo estes resultados similares aos verificados nesta pesquisa, dos quais os cães tinham acesso à rua $\mathrm{e}$ todos eram semidomiciliados, o que representa um importante fator de risco para esta enfermidade.

$\mathrm{O}$ aspecto macroscópico do TVT dos animais desta pesquisa está de acordo com Daleck et al. (2009) e Stockmann et al. (2011b), que relataram tumores com apresentação sólida, hiperêmica, com aumento de volume no local afetado, aspecto de couve-flor, friável e com sangramento. Dos três machos examinados, um animal teve apresentação venérea do tumor (no pênis e prepúcio), e os dois restantes tiveram localização extragenital, um na cavidade nasal e o outro, nodulações subcutâneas (Figura 1). Das sete fêmeas examinadas, todas as apresentações foram genitais.

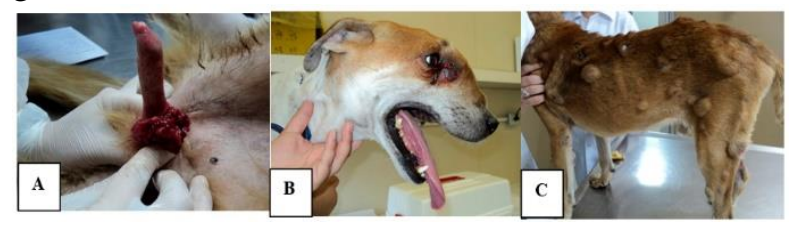

Figura 1. A: Cão, SRD com tumor venéreo transmissível (TVT) genital. B: Cão, SRD com aumento de volume na região do plano nasal. C: Cão, SRD com Tumor venéreo transmissível (TVT) cutâneo.

Em relação à distribuição da localização tumoral, verificou-se que $80 \%$ dos cães tinham acometimento genital, $20 \%$ apresentavam nodulações cutâneas, 10\% tinham lesões nasais, enquanto que $10 \%$ apresentaram a localização cutânea e nasal, simultaneamente. Os achados deste trabalho são similares a Chiti e Amber (1992); Rogers et al. (1998); Sousa et al. (2000); Gurel et al. (2002); Filgueira (2010) e Lima et al. (2013) quando relataram o TVT extragenital nas cavidades oral e nasal. Rogers et al. (1998) também verificaram a ocorrência nas regiões anal e perianal; conjuntiva ocular; pele e tonsilas. Numa cadela desta pesquisa, observou-se necrose, ulceração e deformidade na genitália e estas alterações foram descritas por Daleck et al. (2009) e Stockmann et al. (2011a).

As alterações clínicas (desidratação, sangramento genital, dispneia, diarreia, inapetência, linfoadenopatia, perda de peso e vômito) observadas antes e após a quimioterapia não apresentaram resultados estatisticamente significativos. Hoque et al. (1995), Martins et al. (2005) e Nak et al. (2005) relataram que animais tratados com o sulfato de vincristina podem apresentar distúrbios gastrointestinais, como náuseas, vômitos e diarreia. Nesta pesquisa, apenas o sangramento vulvar apresentou diferenças estatisticamente significativas $(\mathrm{p}<0,05)$ após 21 dias da aplicação do quimioterápico, o que demonstrou uma resposta efetiva ao tratamento.

O sulfato de vincristina, apesar da baixa toxicidade, pode causar alopecia, poliúria, febre, hipertensão, convulsão, disúria e paresia, devido à neuropatia periférica (Martins et al., 2005) e mielossupressão (Martins et al., 2005; Nak et al., 2005). Martins et al. (2005) relataram leucopenia e emese em 5 a $7 \%$ dos cães tratados com esse fármaco. Nak et al. (2005) verificaram perda de peso e anorexia, depressão e paralisia, bem como alterações quantitativas e qualitativas do sêmen de cães tratados com sulfato de vincristina.

Antes do tratamento, no presente estudo, a área média dos tumores de oito cães era de $8,6 \pm$ 5,3; após sete dias, a média foi de 2,7 $\pm 1,3 ; 14$ dias foi de $1,1 \pm 1,1 ; 21$ dias $0,6 \pm 0,9 ; 28$ dias $0,1 \pm 0,2$ e após 35 dias, a média foi de $0,0 \pm 0,0$. Essa regressão demonstrou que os cães responderam ao tratamento quimioterápico, sendo observada remissão completa do tumor em $100 \%$ dos animais em seis semanas, conforme descrito por Lorimier e Fan (2007). Nesta pesquisa, em dois animais não foi possível calcular o tamanho do tumor, mas observou-se visualmente sua redução. Um animal era portador do TVT com comprometimento nasal, e antes da $6^{\mathrm{a}}$ aplicação, houve o desaparecimento de toda a massa tumoral, enquanto que o outro apresentou nodulações subcutâneas generalizadas 
pelo corpo, e após o tratamento houve o desaparecimento completo do tumor.

O TVT é classificado com base nas células predominantes em linfoide, plasmocitoide ou misto (Stockmann et al., 2011a; Flórez et al., 2012; Lima et al., 2013). Dos cinco cães portadores do tipo plasmocitário, nenhum apresentou resistência ao quimioterápico, contradizendo afirmações de Flórez et al. (2012) e Lima et al. (2013) que descreveram que a quimiorresistência se deve ao aumento da expressão de glicoproteína $P$, que age no fluxo de alguns quimioterápicos como vincristina e doxorrubicina (Amaral et al., 2004).

O diagnóstico do TVT foi confirmado por citologia por análise de imprint e pelo método de citologia por agulha fina. A Figura 2A apresenta a população neoplásica de células arredondadas individualizadas, com citoplasma moderado, levemente azulado e com numerosos microvacúolos; núcleo arredondado, excêntrico, apresentando cromatina grosseiramente reticular caracterizando o TVT do tipo plasmocitário. Nessa classificação as células apresentam acentuada anisocitose, anisocariose e mínimo pleomorfismo nuclear. No fundo da lâmina, observam-se numerosas hemácias e neutrófilos hipersegmentados e raros degenerados. Conforme descreveram Amaral et al. (2004), o tumor plasmocitário é descrito quando ao menos $70 \%$ das células neoplásicas se apresentam ovoides, com menor relação núcleo: citoplasma e núcleo excêntrico. Stockmann et al. (2011a) citaram que no tumor do tipo plasmocitário, a maioria das células tem uma morfologia ovoide (mais de $60 \%$ ). Flórez et al. (2012) e Lima et al. (2013) verificaram uma menor relação núcleo: citoplasma e núcleo excêntrico localizado.

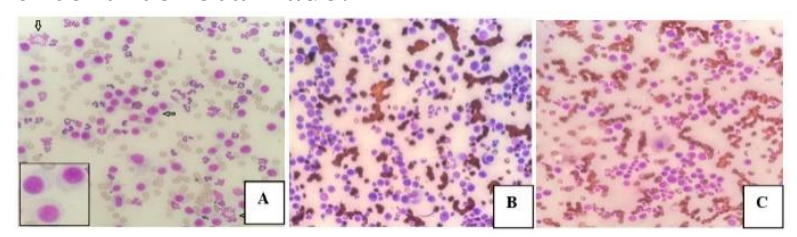

Figura 2. A: Tumor venéreo transmissível (TVT) do tipo plasmocitário apresentando citoplasma moderado, contorno ovoide e núcleo arredondado e excêntrico - Numerosas mitoses típicas (seta central) e atípicas (setas nas extremidades). Numerosos microvacúolos (detalhe à esquerda). Diff quick, aumento 400x. B: Tumor venéreo transmissível (TVT) do tipo linfocitário, onde é observado contorno celular, arredondado e núcleo centralizado e menor relação núcleo-citoplasma. Diff quick, aumento 400x. C: TVT do tipo misto. Diff quick, aumento 400x.
A Figura 2B mostra as características citológicas do TVT tipo linfocitário com células neoplásicas predominantemente com citoplasma escasso e vacuolizado, semelhante à descrição de Amaral et al. (2004) que classificaram o TVT de aspecto linfocitário quando no mínimo $70 \%$ das células tumorais se assemelham a linfócitos, ou seja, células arredondadas, com maior relação núcleo: citoplasma e núcleo redondo e central. O tipo linfoide inclui predominantemente células com uma morfologia arredondada (Stockmann et al., 2011a), composto por mais de $60 \%$ de núcleos escassos e citoplasma finamente granular, presença de vacúolos, com cromatina grosseira e de um ou dois nucléolos evidentes (Flórez et al., 2012; Lima et al., 2013).

A Figura $2 \mathrm{C}$ demonstra as características citológicas do TVT tipo misto (ou linfoplasmocitário) concordando com Amaral et al. (2004). Estes autores descreveram que quando ambos os tipos celulares estão presentes em um percentual inferior a 70\%, o TVT se classifica como linfoplasmocitário ou misto. O tipo misto tem exposições mistas de celularidade (Stockmann et al., 2011a) não ultrapassando de 59\% cada tipo (Flórez et al., 2012; Lima et al. 2013).

$\mathrm{Na}$ Tabela 1 se encontram os resultados do hemograma dos cães antes e após o tratamento com o sulfato de vincristina. Na série vermelha não foram verificadas alterações significativas, concordando com Mukaratirwa et al. (2006) que não detectaram diferenças significativas entre os valores hematológicos de cães com TVT tanto na progressão como na regressão do tumor. Entretanto, Daleck et al. (2009) relataram policitemia e aumento na eritropoietina em cães, podendo ser atribuídos à síntese desse hormônio pelas células de TVT.

A ausência de alterações hematológicas nesta pesquisa está de acordo com Camacho e Laus (1987), Camacho e Santana (1992) e Santana (2000), que verificaram não haver alteração significativa entre os valores médios eritrocitários medular e periférico em cães portadores de TVT tratados com sulfato vincristina na dose de 0,025 $\mathrm{mg} / \mathrm{kg}$ de peso corpóreo, semanalmente, durante quatro semanas. No entanto, Jain (1993) encontrou na contagem eritrocitária diminuição constante do número de hemácias para valores abaixo daqueles de referência. 
Tabela 1. Média e desvio-padrão de variáveis hematológicas de 10 cães com tumor venéreo transmissível (TVT) antes e após o tratamento com sulfato de vincristina

\begin{tabular}{|c|c|c|c|c|c|c|c|c|}
\hline $\begin{array}{c}\text { Variáveis } \\
\text { Hematológicas }\end{array}$ & Referência & Antes & $\begin{array}{l}\text { Após } \\
7 \text { dias }\end{array}$ & $\begin{array}{l}\text { Após } \\
14 \text { dias }\end{array}$ & $\begin{array}{l}\text { Após } \\
21 \text { dias }\end{array}$ & $\begin{array}{c}\text { Após } \\
28 \text { dias }\end{array}$ & $\begin{array}{c}\text { Após } \\
\text { 35 dias }\end{array}$ & p-valor \\
\hline Hemácias $\left(\mathbf{x 1 0}^{6}\right)$ & $5,0-8,5$ & $5,6 \pm 1,4$ & $5,4 \pm 1,1$ & $5,5 \pm 1,1$ & $5,6 \pm 1,0$ & $5,4 \pm 1,2$ & $5,6 \pm 1,0$ & $0,998 \mathrm{~ns}$ \\
\hline Hemoglobina (g/dl) & $12-18$ & $\begin{array}{c}12,6 \pm \\
2,8\end{array}$ & $\begin{array}{c}12,4 \pm \\
2,3\end{array}$ & $\begin{array}{c}12,0 \pm \\
2,5\end{array}$ & $\begin{array}{c}12,0 \pm \\
2,2\end{array}$ & $\begin{array}{c}11,6 \pm \\
2,7\end{array}$ & $\begin{array}{c}11,6 \pm \\
2,3\end{array}$ & $0,915 \mathrm{~ns}$ \\
\hline Hematócrito (\%) & $37-55$ & $\begin{array}{c}37,6 \pm \\
7,6\end{array}$ & $\begin{array}{c}36,8 \pm \\
7,2\end{array}$ & $\begin{array}{c}34,9 \pm \\
6,5\end{array}$ & $\begin{array}{c}35,5 \pm \\
6,0\end{array}$ & $\begin{array}{c}34,9 \pm \\
6,7\end{array}$ & $\begin{array}{c}34,7 \pm \\
6,7\end{array}$ & $0,903 \mathrm{~ns}$ \\
\hline VCM (fl) & $60-77$ & $\begin{array}{l}68,4 \\
\pm 5,7\end{array}$ & $\begin{array}{r}68,1 \\
\pm 5,6\end{array}$ & $\begin{array}{r}64,4 \\
\pm 4,8\end{array}$ & $\begin{array}{l}63,7 \\
\pm 3,2\end{array}$ & $\begin{array}{r}64,8 \\
\pm 4,3\end{array}$ & $\begin{array}{r}62,9 \\
\pm 3,8\end{array}$ & $0,420 \mathrm{~ns}$ \\
\hline СHCM (\%) & $32-36$ & $\begin{array}{l}33,3 \\
\pm 1,1\end{array}$ & $\begin{array}{r}33,6 \\
\pm 1,3\end{array}$ & $\begin{array}{r}34,3 \\
\pm 1,8\end{array}$ & $\begin{array}{r}33,6 \\
\pm 1,3\end{array}$ & $\begin{array}{l}32,9 \\
\pm 1,8\end{array}$ & $\begin{array}{r}33,3 \\
\pm 1,0\end{array}$ & $0,350 \mathrm{~ns}$ \\
\hline Plaquetas $\left(\mathbf{x 1 0}^{3}\right)$ & $200-500$ & $\begin{array}{c}272,5 \pm \\
179,5\end{array}$ & $\begin{array}{c}274,2 \pm \\
109,1\end{array}$ & $\begin{array}{c}229,4 \pm \\
134,4\end{array}$ & $\begin{array}{c}197,9 \pm \\
79,1\end{array}$ & $\begin{array}{c}150,4 \pm \\
76,9\end{array}$ & $\begin{array}{c}212,6 \pm \\
61,4\end{array}$ & $0,148 \mathrm{~ns}$ \\
\hline Bastonetes (\%) & $0-3$ & $3,3 \pm 5,0$ & $2,7 \pm 6,5$ & $1,3 \pm 1,8$ & $1,5 \pm 1,4$ & $0,8 \pm 0,8$ & $2,0 \pm 3,4$ & $0,687 \mathrm{~ns}$ \\
\hline Bastonetes $(\mu \mathrm{L})$ & $0-300$ & $\begin{array}{c}1.396,2 \\
\pm \\
1.704,1 \\
\mathbf{a}\end{array}$ & $\begin{array}{c}3.113,0 \\
\pm \\
5.933,3 \\
\mathbf{a}\end{array}$ & $\begin{array}{c}172,6 \\
\pm \\
125,0 \\
\mathbf{b}\end{array}$ & $\begin{array}{c}214,4 \\
\pm \\
142,6 \\
\text { b }\end{array}$ & $\begin{array}{c}139,3 \\
\pm \\
74,8 \\
\mathbf{b}\end{array}$ & $\begin{array}{c}474,0 \\
\pm \\
753,2 \\
\text { b }\end{array}$ & $0,042 *$ \\
\hline Linfócitos (\%) & $12-30$ & $\begin{array}{l}25,1 \\
\pm 9,5\end{array}$ & $\begin{array}{c}31,1 \\
\pm 16,2\end{array}$ & $\begin{array}{c}23,3 \\
\pm 12,2\end{array}$ & $\begin{array}{r}26,8 \\
\pm 5,5\end{array}$ & $\begin{array}{r}25,0 \\
\pm 8,4\end{array}$ & $\begin{array}{r}27,5 \\
\pm 7,9\end{array}$ & $0,654 \mathrm{~ns}$ \\
\hline Linfócitos $(\mu \mathrm{L})$ & $1.000-4.800$ & $\begin{array}{c}4.064,2 \pm \\
1.525,7\end{array}$ & $\begin{array}{c}3.602,1 \pm \\
3.229,9\end{array}$ & $\begin{array}{c}2.434,5 \pm \\
1.989,9\end{array}$ & $\begin{array}{c}2.584,9 \pm \\
964,7\end{array}$ & $\begin{array}{c}2.307,2 \pm \\
904,9\end{array}$ & $\begin{array}{c}2.697,7 \pm \\
966,3\end{array}$ & $0,184 \mathrm{~ns}$ \\
\hline Eosinófilos (\%) & $2-10$ & $6,1 \pm 6,0$ & $2,8 \pm 2,2$ & $4,5 \pm 5,8$ & $5,3 \pm 3,0$ & $6,7 \pm 8,1$ & $3,7 \pm 2,8$ & $0,531 \mathrm{~ns}$ \\
\hline Eosinófilos $(\mu \mathrm{L})$ & $150-1250$ & $\begin{array}{c}980,1 \pm \\
968,3\end{array}$ & $\begin{array}{c}233,5 \pm \\
193,1\end{array}$ & $\begin{array}{c}403,9 \pm \\
643,5\end{array}$ & $\begin{array}{c}507,5 \pm \\
337,1\end{array}$ & $\begin{array}{c}563,7 \pm \\
498,3\end{array}$ & $\begin{array}{c}379,6 \pm \\
314,5\end{array}$ & $0,076 \mathrm{~ns}$ \\
\hline Monócitos (\%) & $3,0-10,0$ & $5,4 \pm 3,5$ & $8,2 \pm 5,7$ & $6,7 \pm 5,3$ & $4,9 \pm 2,5$ & $3,4 \pm 1,6$ & $6,4 \pm 3,8$ & $0,151 \mathrm{~ns}$ \\
\hline Monócitos $(\mu \mathrm{L})$ & $150-1.350$ & $\begin{array}{c}841,8 \pm \\
484,1\end{array}$ & $\begin{array}{c}1.062,3 \pm \\
1.159,4\end{array}$ & $\begin{array}{c}700,1 \pm \\
722,8\end{array}$ & $\begin{array}{l}462,3 \pm \\
230,5\end{array}$ & $\begin{array}{c}319,7 \pm \\
180,8\end{array}$ & $\begin{array}{c}647,9 \pm \\
477,3\end{array}$ & $0,141 \mathrm{~ns}$ \\
\hline Basófilos $(\mu \mathrm{L} / \%)$ & raros & $0,0 \pm 0,0$ & $0,0 \pm 0,0$ & $0,0 \pm 0,0$ & $0,0 \pm 0,0$ & $0,0 \pm 0,0$ & $0,0 \pm 0,0$ & - \\
\hline Segmentados $(\%)$ & $60-77$ & $\begin{array}{c}59,8 \pm \\
9,1\end{array}$ & $\begin{array}{c}54,8 \pm \\
18,7\end{array}$ & $\begin{array}{c}64,2 \pm \\
14,0\end{array}$ & $\begin{array}{c}61,5 \pm \\
5,0\end{array}$ & $\begin{array}{c}66,8 \pm \\
9,4\end{array}$ & $\begin{array}{c}60,2 \pm \\
7,9\end{array}$ & $0,295 \mathrm{~ns}$ \\
\hline Segmentados $(\mu \mathrm{L})$ & $\begin{array}{l}3.000- \\
11.400\end{array}$ & $\begin{array}{r}10.638,3 \\
\pm 4.909,3\end{array}$ & $\begin{array}{c}7.234,3 \pm \\
7.684,3\end{array}$ & $\begin{array}{c}5.890,7 \pm \\
1.854,1\end{array}$ & $\begin{array}{c}5.825,2 \pm \\
1.647,1\end{array}$ & $\begin{array}{c}6.120,8 \pm \\
2.454,2\end{array}$ & $\begin{array}{c}6.624,2 \pm \\
3.664,6\end{array}$ & $0,118 \mathrm{~ns}$ \\
\hline
\end{tabular}

* Significativo $(\mathrm{p}<0.05)$; ns- não significativo;

a,b - letras minúsculas diferentes diferem estatisticamente pelo Teste de comparações múltiplas de Tukey.

Em relação à contagem de plaquetas, observou-se trombocitopenia na quarta e quinta semana de tratamento. Esses resultados foram compatíveis com Diniz et al. (1999) que observaram que o sulfato de vincristina causa trombocitopenia, e com os de Olgivie (1996) quando este afirmou que essa alteração é um achado marcante nos animais com TVT, por mecanismos relacionados com o aumento do consumo ou sequestro de plaquetas.

$\mathrm{Na}$ série leucocitária, apenas os bastonetes sofreram influência dos tratamentos $(\mathrm{p}=0,042)$, diminuindo no início e após sete dias. Essa alteração inicial dos bastonetes se deve provavelmente ao processo inflamatório agudo associado à presença do tumor, em que $\mathrm{o}$ organismo recrutou mais células de defesas, causando um aumento significativo. Após a quimioterapia, houve a regressão do tumor e da inflamação e consequentemente, ocorreu a diminuição do valor absoluto dessa célula. As demais variáveis leucocitárias não apresentaram diferenças estatisticamente significantes. Estudos mostraram ocorrer diminuição significativa nas contagens totais de leucócitos com a utilização do sulfato de vincristina (Daleck, 1986; Camacho e Laus, 1987; O'keefe e Harrys, 1990; Camacho e Santana, 1992; Dinesh et al. 1993; Faro et al., 2008).

A leucopenia secundária resultante do quimioterápico representa um fator limitante no tratamento (Faro et al., 2008). Calvert et al. (1982) relataram leucopenia em 5\% dos cães tratados com sulfato de vincristina, enquanto que Erunal-Maral et al. (2000) encontraram neutropenia em $25 \%$ dos casos tratados. Nak et al. (2005) verificaram 
leucopenia, neutropenia, linfocitose, anemia e trombocitopenia nos cães tratados com o sulfato de vincristina.

Quanto ao perfil bioquímico dos animais com TVT, as referências são escassas (Daleck et al., 2009), e comumente não ocorrem alterações significativas (Tilley e Smith Jr., 2008). Considerando que a dose utilizada do sulfato de vincristina foi à dose máxima recomendada, observou-se nesta pesquisa, que não houve alterações bioquímicas importantes (Tabela 2) e esses resultados estão compatíveis com a literatura consultada, que sugeriu que este fármaco tem baixa toxicidade (Daleck et al., 2009).

$\mathrm{Na}$ avaliação bioquímica dos cães antes e após o tratamento com o sulfato de vincristina foi observado que apenas o aumento do fósforo foi estatisticamente significativo $(p<0,05)$, sofrendo influência dos tratamentos $(\mathrm{p}=0,024)$. No início e após 21 dias, os valores estavam acima do parâmetro de referência e nos demais dias, os valores estavam dentro da normalidade para cães.

Tabela 2. Média e desvio-padrão de variáveis bioquímicas de 10 cães com tumor venéreo transmissível (TVT) antes e após o tratamento com sulfato de vincristina

\begin{tabular}{|c|c|c|c|c|c|c|c|c|}
\hline Bioquímica & Referência & Antes & $\begin{array}{l}\text { Após } \\
7 \text { dias } \\
\end{array}$ & $\begin{array}{c}\text { Após } \\
14 \text { dias }\end{array}$ & $\begin{array}{c}\text { Após } \\
21 \text { dias } \\
\end{array}$ & $\begin{array}{c}\text { Após } \\
28 \text { dias }\end{array}$ & $\begin{array}{c}\text { Após } \\
35 \text { dias }\end{array}$ & p-valor \\
\hline Ácido úrico (mg/dL) & $0-2$ & $0,4 \pm 0,2$ & $0,4 \pm 0,2$ & $0,4 \pm 0,2$ & $0,3 \pm 0,2$ & $0,3 \pm 0,3$ & $0,5 \pm 0,5$ & $0,645 \mathrm{~ns}$ \\
\hline Albumina (g/dL) & $2,3-3,8$ & $\begin{array}{c}2,9 \pm \\
0,3\end{array}$ & $\begin{array}{c}2,8 \pm \\
0,4\end{array}$ & $2,8 \pm 0,4$ & $2,9 \pm 0,4$ & $\begin{array}{c}2,6 \pm \\
0,6\end{array}$ & $2,5 \pm 0,6$ & $0,496 \mathrm{~ns}$ \\
\hline Globulinas (UI/L) & $2,3-5,2$ & $\begin{array}{c}7,3 \pm \\
2,2\end{array}$ & $\begin{array}{c}6,5 \pm \\
2,1\end{array}$ & $\begin{array}{c}6,4 \pm \\
1,6\end{array}$ & $\begin{array}{c}6,5 \pm \\
1,8\end{array}$ & $\begin{array}{c}5,7 \pm \\
1,6\end{array}$ & $5,8 \pm 1,4$ & $0,447 \mathrm{~ns}$ \\
\hline $\begin{array}{l}\text { Proteína Total (Soro) } \\
\text { (g/dL) }\end{array}$ & $5,4-7,7$ & $\begin{array}{c}10,1 \pm \\
2,0\end{array}$ & $\begin{array}{c}9,3 \pm \\
2,0\end{array}$ & $\begin{array}{c}9,2 \pm \\
1,4\end{array}$ & $\begin{array}{c}9,4 \pm \\
1,7\end{array}$ & $\begin{array}{c}8,4 \pm \\
1,6\end{array}$ & $8,3 \pm 1,4$ & $0,166 \mathrm{~ns}$ \\
\hline ALT (UI/L)/TGP & $10-88$ & $\begin{array}{c}40,6 \pm 14 \\
8\end{array}$ & $\begin{array}{c}47,1 \pm 23 \\
5\end{array}$ & $\begin{array}{c}48,8 \pm 21 \\
6\end{array}$ & $\begin{array}{c}41,9 \pm 12 \\
2\end{array}$ & $\begin{array}{l}35,7 \pm 18 \\
3\end{array}$ & $\begin{array}{c}33,4 \pm 16 \\
1\end{array}$ & $0,358 \mathrm{~ns}$ \\
\hline AST (UI/L)/TGO & $10-88$ & $\begin{array}{c}42,4 \pm 12 \\
2\end{array}$ & $\begin{array}{c}40,5 \pm 11 \\
1\end{array}$ & $\begin{array}{c}44,1 \pm 18 \\
0\end{array}$ & $33,2 \pm 9,3$ & $\begin{array}{c}34,1 \\
\pm 14,3\end{array}$ & $\begin{array}{c}29,9 \pm 15 \\
4\end{array}$ & $0,141 \mathrm{~ns}$ \\
\hline Colesterol (mg/dL) & $125-270$ & $\begin{array}{c}188,5 \pm 37 \\
, 0\end{array}$ & $\begin{array}{c}187,0 \pm 48 \\
, 8\end{array}$ & $\begin{array}{c}187,5 \pm 40 \\
, 1\end{array}$ & $\begin{array}{c}186,1 \pm 50 \\
, 7\end{array}$ & $\begin{array}{c}177,1 \pm 42 \\
, 4\end{array}$ & $\begin{array}{c}169,1 \pm 41 \\
, 6\end{array}$ & $0,899 \mathrm{~ns}$ \\
\hline Triglicerídeos (mg/dL) & $20-112$ & $\begin{array}{c}79,2 \pm 44 \\
2\end{array}$ & $\begin{array}{c}67,4 \pm \\
15,1\end{array}$ & $\begin{array}{l}79,5 \pm \\
26,7\end{array}$ & $\begin{array}{c}82,2 \pm 44 \\
0\end{array}$ & $\begin{array}{c}65,7 \pm 13 \\
6\end{array}$ & $\begin{array}{c}62,4 \pm 16 \\
3\end{array}$ & $0,540 \mathrm{~ns}$ \\
\hline Creatinina (mg/dL) & $0,5-1,5$ & $\begin{array}{c}1,0 \pm \\
0,2\end{array}$ & $\begin{array}{c}1,0 \pm \\
0,2\end{array}$ & $\begin{array}{c}1,0 \pm \\
0,2\end{array}$ & $\begin{array}{c}1,1 \pm \\
0,1\end{array}$ & $\begin{array}{c}1,0 \pm \\
0,1\end{array}$ & $\begin{array}{c}1,0 \pm \\
0,2\end{array}$ & $0,745 \mathrm{~ns}$ \\
\hline $\begin{array}{l}\text { Fosfatase Alcalina } \\
\text { (UI/L) }\end{array}$ & $20-150$ & $\begin{array}{c}48,0 \pm 23 \\
1\end{array}$ & $\begin{array}{c}39,7 \pm 11 \\
1\end{array}$ & $\begin{array}{c}49,7 \pm 31 \\
9\end{array}$ & $\begin{array}{c}52,4 \pm \\
24,3\end{array}$ & $\begin{array}{c}51,6 \pm 21 \\
7\end{array}$ & $\begin{array}{c}43,0 \pm 20 \\
1\end{array}$ & $0,783 \mathrm{~ns}$ \\
\hline Ureia (mg/dL) & $20-60$ & $\begin{array}{c}42,0 \pm 17 \\
9\end{array}$ & $\begin{array}{c}44,1 \pm 17 \\
5\end{array}$ & $35,8 \pm 8,0$ & $\begin{array}{l}45,8 \pm 14 \\
5\end{array}$ & $\begin{array}{c}34,4 \pm 13 \\
0\end{array}$ & $\begin{array}{c}37,0 \pm 14 \\
1\end{array}$ & $0,386 n s$ \\
\hline Cálcio (mmol/L) & $8,0-11,2$ & $\begin{array}{c}8,3 \pm \\
1,1\end{array}$ & $\begin{array}{c}8,3 \pm \\
0,7\end{array}$ & $\begin{array}{c}8,3 \pm \\
0,4\end{array}$ & $\begin{array}{c}8,5 \pm \\
0,8\end{array}$ & $\begin{array}{l}7,6 \pm \\
2,8\end{array}$ & $\begin{array}{c}8,6 \pm \\
0,6\end{array}$ & $0,611 \mathrm{~ns}$ \\
\hline Fósforo (mg/dL) & $2,2-5,5$ & $\begin{array}{c}5,9 \pm \\
1,3 \\
\mathbf{a}\end{array}$ & $\begin{array}{c}4,7 \pm \\
0,9 \\
\text { b }\end{array}$ & $\begin{array}{c}4,8 \pm \\
0,7 \\
\text { b }\end{array}$ & $\begin{array}{c}5,8 \pm \\
1,4 \\
\mathbf{a}\end{array}$ & $\begin{array}{c}4,9 \pm \\
0,9 \\
\text { b }\end{array}$ & $\begin{array}{c}5,0 \pm \\
0,6 \\
\text { b }\end{array}$ & $\mathbf{0 , 0 2 4 *}$ \\
\hline Magnésio (mg/dL) & $1,8-2,4$ & $\begin{array}{c}1,7 \pm \\
0,3\end{array}$ & $\begin{array}{c}1,7 \pm \\
0,2\end{array}$ & $\begin{array}{c}1,7 \pm \\
0,3\end{array}$ & $\begin{array}{c}1,7 \pm \\
0,2\end{array}$ & $\begin{array}{c}1,8 \pm \\
0,3\end{array}$ & $\begin{array}{c}1,8 \pm \\
0,3\end{array}$ & $0,913 \mathrm{~ns}$ \\
\hline Potássio (mg/dL) & $4,8-5,4$ & $\begin{array}{c}4,5 \pm \\
0,4\end{array}$ & $\begin{array}{c}4,6 \pm \\
0,3\end{array}$ & $\begin{array}{c}4,4 \pm \\
0,5\end{array}$ & $\begin{array}{c}4,7 \pm \\
0,6\end{array}$ & $\begin{array}{c}4,4 \pm \\
0,6\end{array}$ & $\begin{array}{c}4,3 \pm \\
0,4\end{array}$ & $0,399 \mathrm{~ns}$ \\
\hline Sódio (mg/dL) & $141-152$ & $\begin{array}{c}144,3 \pm 3 \\
5\end{array}$ & $\begin{array}{l}142,9 \pm 5 \\
5\end{array}$ & $\begin{array}{c}140,2 \pm 4 \\
0\end{array}$ & $\begin{array}{c}143,1 \pm 5 \\
7\end{array}$ & $\begin{array}{c}139,5 \pm 7 \\
7\end{array}$ & $\begin{array}{c}143,7 \pm 4 \\
1\end{array}$ & $0,245 \mathrm{~ns}$ \\
\hline
\end{tabular}

* Significativo ( $\mathrm{p}<0.05$ ); ns- não significativo.

a,b - letras minúsculas diferentes diferem estatisticamente pelo Teste de comparações múltiplas de Tukey.

A hiperfosfatemia pode estar associada às insuficiências renais, em que ocorre retenção desse elemento (Ferreira Neto et al., 1978), porém apesar do aumento do fósforo poder ser decorrente do efeito nefrotóxico do sulfato de vincristina, as avaliações de uréia e creatinina estarem dentro dos valores de referência em todos os momentos avaliados. A hiperfosfatemia também pode estar relacionada com a síndrome de lise tumoral principalmente nos casos associados à quimioterapia das neoplasias que acometem os mieloblastos ou linfoblastos (Jericó et al., 2015).

A dosagem dos eletrólitos como o cálcio, magnésio, potássio e sódio não apresentaram 
alterações significativas. Os resultados obtidos para o ácido úrico apresentaram pouca variação, ao contrário do colesterol, em que os valores foram diminuindo gradativamente durante o tratamento. Os triglicerídeos se apresentaram alterados em vários momentos, porém se mantendo dentro dos valores de referência (Kaneko et al., 2008).

\section{Conclusão}

O tumor venéreo transmissível (TVT) é uma neoplasia frequente na casuística clínica de pequenos animais que resulta em alterações clínicas, hematológicas, bioquímicas e citopatológicas nos cães acometidos. Nos 10 cães dessa pesquisa, independente da classificação tumoral, houve resposta satisfatória ao tratamento instituído com o sulfato de vincristina. A partir de seis aplicações do quimioterápico, com intervalos de sete dias entre as aplicações, houve regressão completa da neoplasia em todos os cães.

\section{Conflito de Interesse}

Os autores declaram não existir conflito de interesse.

\section{Comitê de Ética}

A pesquisa foi aprovada pela Comissão de Ética no Uso de Animais (CEUA/UFRPE), sob o número 23082.024378/2015-26.

\section{Referências}

Alleman, A.R.; Harvey, J.W. The morphologic effects of vincristine sulfate on canine bone marrow cells. Veterinary Clinical Pathology, 22(2): 36-41, 1993.

Amaral, A S.; Gaspar, L.F.J.; Silva, S.B.; Rocha, N.S. Diagnóstico citológico do tumor venéreo transmissível na região de Botucatu, Brasil: estudo descritivo 1994-2003. Revista Portuguesa de Ciência Veterinária, 99(551): 167-171, 2004.

Calvert, C.A.; Leifer, C.E.; MacEwen, E.G. Vincristine for treatment of transmissible venereal tumours in the dog. Journal of the American Veterinary Medical Association, 181: 163-164, 1982.

Camacho, A.A.; Laus, J.L. Estudo sobre a eficiência da vincristina no tratamento de cães com tumor venéreo transmissível. Ars Veterinária, 3(1): 37-42, 1987.

Camacho, A.A.; Santana, A.E. Alterações da medula óssea e do sangue periférico de cães induzidas pela vincristina. Ciência Veterinária, 6(2): 1-11, 1992.

Chiti, L.; Amber, E.I. Incidence of tumors seen at the Faculty of Veterinary Medicine, University of Zambia: a four year retrospective study. Zimbabwe Veterinary Journal, 3: 143-147, 1992.

Daleck, C.L.M. Emprego do sulfato de vincristina no tratamento do tumor venéreo transmissível canino. Belo Horizonte. 1986. 53 f. Dissertação (Mestrado) - Universidade Federal de Minas Gerais, Belo Horizonte, 1986.

Daleck, C. R.; De Nardi, A. B.; Rodaski, S. Oncologia em cães e gatos. São Paulo: Roca, 2009. 612p.

Diniz, P.P.V.P.; Camacho, A.A.; Santana, A.E.; Sobreira, M.F.R.; Velasque, F.G. Eletrocardiografia e avaliação das enzimas musculares em cães tratados com sulfato de vincristina. Ars Veterinaria, 15(3): 170176, 1999.

Erunal-Maral, N.; Findik, M.; Aslan, S. Use of exfoliative cytology for diagnosis of transmissible venereal tumour and controlling the recovery period in the bitch. Deutsche Tierarztliche Wochenschrift, 107:175-180, 2000.

Faro, A.M.; Daleck, C.R.; Santana, A.E; Nardi, A.B.; Motta, F.R.; Eurides, D. Avaliação hematológica em cães submetidos ao tratamento quimioterápico com sulfato de Vincristina, Prednisona e Ciclofosfamida: estudo experimental. Ars Veterinaria, 24(1): 001-008, 2008.

Ferreira Neto, J.M.F.; Viana, E.S.; Magalhães, L.M. Patologia clínica veterinária. Belo Horizonte: Rabelo e Brasil, 1978. 279 p.

Filgueira, K.D. Tumor venéreo transmissível canino com localização primária e única em cavidade oral. Acta Scientiae Veterinariae, 38: 91-94, 2010.

Flores, P.E.; Diez, Y.X.; Diaz, R.A.M.; Urcelay, V.S.; Cattaneo, U.G. Comparison of the neoplasms recorded in two periods (19811985 and 1986-1988) at the surgery section of the Faculty of Veterinary Medicine. Chile Avances en Ciencias Veterinarias University, 8(1): 61-65, 1993.

Flórez, M.M., Pedraza, F., Grandi, F., Rocha, N.S. Cytogogic subtypes of canine transmissible venereal tumor. Veterinary Clinical Pathology, 41(1): 4-5, 2012. 
Gandotra, V.K.; Prabhakar, S.; Singla, V.K.; Chauhan, F.S.; Sharma, R.D. Incidence of physio-pathological reproductive problems in canines. Indian Veterinary Journal, 70(5): 467, 1993.

Gurel, A.; Kuscu, B.; Gulanber, E.G.; Arun, S.S. Transmissible venereal tumors detected in the extragenital organs of dogs. Israel Journal Veterinary Medicine, 57: 1-8, 2002.

Hoque, M.; Singh, G.R.; Pawde, A. Electrosurgery versus scalpel surgery in canine transmissible venereal tumor. Indian Journal of Veterinary Research, 4: 51-54, 1995.

Jain, N.C. Essentials of veterinary hematology. Philadelphia: Lea \& Febiger, 1993. 417 p.

Jericó, M.M; Andrade Neto, J.P.A.; Kogica, M.M. Tratado de medicina interna de cães e gatos. São Paulo: Roca, 2015. v. 2, 2394p.

Johnson, C.A. Infecções genitais e tumor venéreo transmissível. In: Nelson, R.W.; Couto, C.G. Fundamentos de medicina interna de pequenos animais. Rio de Janeiro: Guanabara Koogan, 1994. p. 522- 525.

Kaneko, J.J.; Harvey, J.W.; Bruss, M.L. Clinical biochemistry of domestic animals. 6 . ed. San Diego: Academic Press, 2008. 916 p.

Lima, E.R.; Almeida, E.L.; Freitas, A.A.; Menezes, M.M.; Pereira, M.F.; Fukahori, F.L.P. Frequência, aspectos clínicos, diagnóstico e tratamento de tumor venéreo transmissível (TVT) em cães atendidos no Hospital Veterinário da UFRPE, Medicina Veterinária (UFRPE), 5(1): 24-29, 2011.

Lima, T.B.; Marinho, P.V.T.; Lira, R.N.; Jark, P.C; Melo, J.F.P; Oliveira, L.C.R. Apresentação atípica de tumor venéreo transmissível cutâneo em um cão. Veterinária e Zootecnia, 20(1): 57-61, 2013.

Lorimier, L.P.; Fan, T.M. Canine transmissible venereal tumor. In: Withrow, S.J.; Vail, D.M. Small animal clinical oncology. 4. ed. Philadelphia: Elsevier, 2007. p. 799-804.

Martins, M.I.M.; Souza, F.F.; Gobelo, C. The canine transmissible venereal tumor: etiology, pathology, diagnosis and treatment. In: __. Recent advances in small animal reproduction. Ithaca: International Veterinary Information Service, 2005.

Mukaratirwa, S.; Chiwome, T.; Chitanga, S.; Bhebhe, E. Canine transmissible venereal tumors: assessment of mast cell numbers as indicators of the growth phase. Veterinary Research Communications, 30(6): 613621, 2006.

Nak, D. Transmissible venereal tumor in bitch. Saglik Bilimleri. Dergisi, 7: 152-155, 2001.

Nak, D.; Nak, Y.; Cangul I.T., Tuna, B. A clinicopathological study on the effect of vincristine on transmissible venereal tumour in dogs. Journal Veterinary Medicine a Physiology, Pathology, Clinical Medicine, 52: 366-370, 2005.

O'Keefe, D.A.; Harris, C.L. Toxicology of oncologic drugs. Veterinary Clinics of North America, 20(2): 483-504, 1990.

Ogilvie, G.K. Chemotherapy. In: Withrow, J.S, MacEwen, E.G. Small animal clinical oncology. Philadelphia: W.B. Saunders, 1996, 589p.

Rodaski, S.; De Nardi, A.B. Modalidades de quimioterapia. In: Quimioterapia antineoplásica em cães e gatos. São Paulo: Medvet Livros, 2007, 305p.

Rogers, K.S.; Walker, M.A.; Dillon, H.B. Transmissible venereal tumor: a retrospective study of 29 cases. American Animal Hospital Association, 34(6): 463470, 1998.

Rosenthal, R.C. Chemoterapy. In: Ettinger, S.J.; Feldman, E.C. Textbook of veterinary internal medicine: diseases of the $\operatorname{dog}$ and cat. 4. ed. Philadelphia: W.B. Saunders Company, 1995. v. 1, p. 473-484.

Santana, A.E. Efeitos hematotóxicos de dois diferentes níveis de dosagens de sulfato de vincristina (oncovin ${ }^{\circledR}$ ) em cães (Canis familiaris, Linnaeus, 1758). 2000. $106 \mathrm{f}$.. Tese (Livre-Docência em Patologia Clínica Veterinária) - Faculdade de Ciências Agrárias e Veterinárias, Universidade Estadual Paulista, Jaboticabal, 2000.

Silva, M.C.V.; Barbosa, R.R.; Santos, R.C.; Chagas, S.N.; Costa, W.P. Avaliação epidemiológica, diagnóstica e terapêutica do tumor venéreo transmissível (TVT) na população canina atendida no Hospital Veterinário da UFERSA. Acta Veterinaria Brasílica, 1(1): 28-32, 2007.

Sousa, J.; Saito, V.; Nardi, A.B.; Rodaski, S.; Guérios, S.D.; Bacila, M. Características e incidência do tumor venéreo transmissível (TVT) em cães e eficiência da quimioterapia 
e outros tratamentos. Archives of Veterinary Science, 5: 41-48, 2000.

Stockmann, D.; Ferrari, H.F.; Andrade, A.L.; Cardoso, T.C.; Luvizotto, M.C.R. Detection of the tumour suppressor gene TP53 and expression of $\mathrm{p} 53, \mathrm{Bcl}-2$ and $\mathrm{p} 63$ proteins in canine transmissible venereal tumour. Veterinary and Comparative Oncology, 9(4): 251-259, $2011 \mathrm{~b}$.
Stockmann, D.; Ferrari, H.F.; Andrade, A.L.; Lopes, R.A.; Cardoso, T.C.; Luvizotto, M.C.R. Canine transmissible venereal tumors: aspects related to programmed cell death. Brazilian Journal Veterinary Pathology, 4(1): 67-75, 2011a.

Tilley, L.P.; Smith Jr., F.W.K. Consulta veterinária em 5 minutos. 3. ed. São Paulo: Manole, 2008. 1550p. 